\title{
Dentigerous cyst in a young child
}

\author{
Levent Demiriz ${ }^{1}$, Ahmet Ferhat Misir², Durmus Ilker Gorur ${ }^{3}$
}

Correspondence: Dr. Levent Demiriz

'Department of Pedodontics, Faculty of Dentistry, Bülent Ecevit University, Zonguldak, Turkiye, ${ }^{2}$ Department of Oral and Maxillofacial Surgery, Faculty of Dentistry, Bülent Ecevit University,

Zonguldak, Turkiye,

Email: drleventdemiriz@gmail.com

${ }^{3}$ Department of Oral and Maxillofacial Surgery, Faculty of Dentistry, Ankara University, Ankara, Turkiye

\section{ABSTRACT}

Dentigerous cyst is a type of odontogenic cysts and generally occurs in the ages of twenties or thirties. Dentigerous cyst always includes a tooth which cannot complete the eruption process and occurs around the crown by the fluid accumulation between the layers of enamel organ. In rare cases, dentigerous cyst occurs in the first decade of life and develops in an immature permanent tooth as a result of a chronic inflammation of overlying nonvital primary tooth. In this report, a case of dentigerous cyst in primary dentition in a 5-year-old child patient and its treatment were presented. The dentigerous cyst was totally enucleated, and the unerupted permanent first premolar tooth was removed from the primary mandibular right premolar region. There was no recurrence observed after 18 months follow-up.

Key words: Child, dentigerous cyst, enucleation, unerupted tooth

\section{INTRODUCTION}

Dentigerous cyst is a type of odontogenic cysts and has a rate between $20 \%$ and $24 \%$ in all the jaw cysts. ${ }^{[1]}$ These cysts form between the enamel epithelium and the enamel of the crown of the affected tooth, and the fluid accumulation occurs in the related area. ${ }^{[2-4]}$ Dentigerous cyst always includes the crown of an unerupted or impacted tooth, and it is commonly observed in the mandibular third molar region..$^{[2-5]}$ These cyst often show no symptoms, and they are generally detected by a radiographic examination to find the reason for the delayed eruption. In the radiographic examination, dentigerous cyst lesion has a well-defined sclerotic border, and a well-demarcated unilocular radiolucency which is surrounding the crown of an unerupted tooth is observed..$^{[2,6,7]}$

The ages of twenties or thirties are the most common periods when the ages of the dentigerous cyst cases are considered whereas these cysts are rare in the first decade. ${ }^{[3,8]}$ Different options were advised for the treatment of these cysts such as the elimination of the damage on the affected permanent tooth, enucleation of all pathological tissues with the removal of the involved tooth, or marsupialization. In these options, the removal of the cystic lesion and the extraction of the unerupted tooth is the main treatment to prevent the recurrence of the cystic lesion. ${ }^{[1,7,9]}$ The aim of this report is to present a case of dentigerous cyst with an unerupted mandibular left first premolar and its surgical treatment in a child patient.

\section{CASE REPORT}

A 5-year-old female child patient referred to the Department of Pedodontics because of a painless swelling in the right side of the mandible for the last 6 months. On general examination, the patient was apparently healthy without any significant past medical history and routine hematological tests were within the normal limits. Extraoral examination

This is an open access article distributed under the terms of the Creative Commons Attribution-NonCommercial-ShareAlike 3.0 License, which allows others to remix, tweak, and build upon the work non-commercially, as long as the author is credited and the new creations are licensed under the identical terms.

For reprints contact: reprints@medknow.com

How to cite this article: Demiriz L, Misir AF, Gorur DI. Dentigerous cyst in a young child. Eur J Dent 2015;9:599-602.

DOI: $10.4103 / 1305-7456.172619$ 
revealed a swelling present near the lower margin of the right mandible. Intraoral examination revealed a hard swelling which caused bulging of the cortical bone in the primary mandibular right first molar region. The primary mandibular right first molar tooth was nonvital, and the crown had been eradicated by a carious lesion. The adjacent mucosa was apparently normal, and there were not any signs of inflammation.

Panoramic radiograph [Figure 1] was taken for radiological examination, and it revealed the presence of a unilocular radiolucent cystic lesion with sclerotic border associated with the mandibular right first premolar crown. The crown of the mandibular right first premolar was lying horizontally and coronally displaced. Additionally, the radiolucent cystic lesion extended to the lower border of the mandible. After the clinical and radiological examination, a provisional diagnosis of the dentigerous cyst was made.

Surgical enucleation of the cyst was chosen as the treatment of choice. The surgical intervention was carried out with a general anesthesia. The primary mandibular right first molar tooth was extracted before the disclosing of the cyst cavity by opening a flap. After the flap opening process, the cyst cavity was identified [Figure 2], and the contents of the cyst were removed with the unerupted premolar tooth [Figure 3]. The flap was sutured for closing the wound primarily. The specimen was prepared and sent for histopathological examination. Histopathological view showed nonkeratinizing stratified squamous epithelium and confirmed the diagnosis of dentigerous cyst [Figure 4]. Appointments were organized in every 3 months for clinical and radiological follow-ups. After 18 months, there was not any recurrence in the operation region [Figure 5].

\section{DISCUSSION}

Dentigerous cysts most commonly occur in the in the ages of twenties or thirties. ${ }^{[5,8,10]}$ However, the frequency in children is relatively low, and 4-9\% of these cysts occur in the first 10 years after birth. ${ }^{[9]}$ In the present case, the cyst was associated with the mandibular first permanent premolar tooth crown in a 5-year-old child.

Two types of dentigerous cysts are reported in the literature: Developmental and inflammatory types. The developmental type of these cysts is the most common type, which surrounds the crown

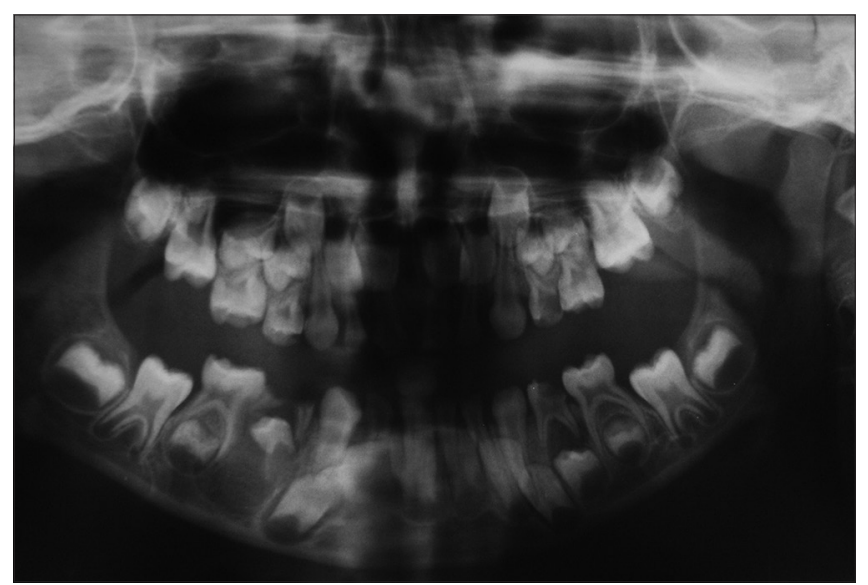

Figure 1: Panoramic radiograph showing the radiolucent area with the displacement of underlying premolar

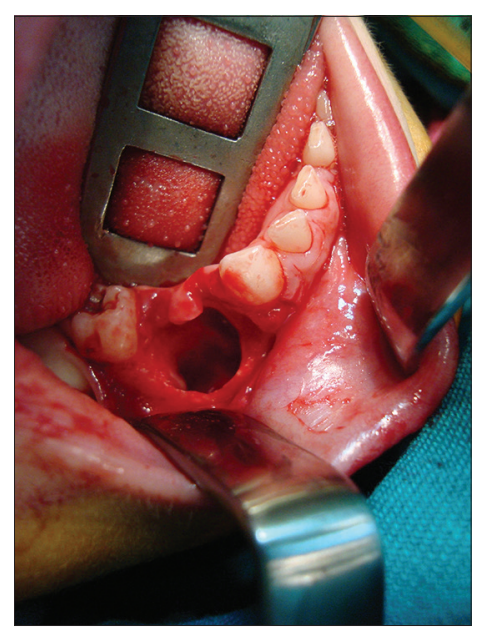

Figure 2: Intraoperative view of the cyst cavity

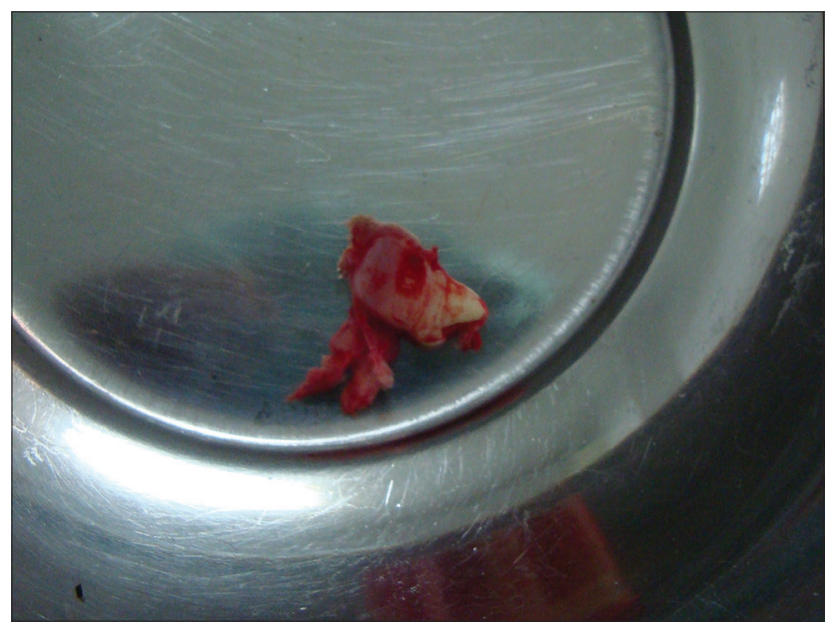

Figure 3: View of the unerupted tooth crown and cystic contents

of an unerupted tooth by the fluid accumulation between the layers of the enamel organ. ${ }^{[1-3]}$ Rarely, the dentigerous cyst develops as a result of periapical inflammation from a nonvital primary tooth. The 


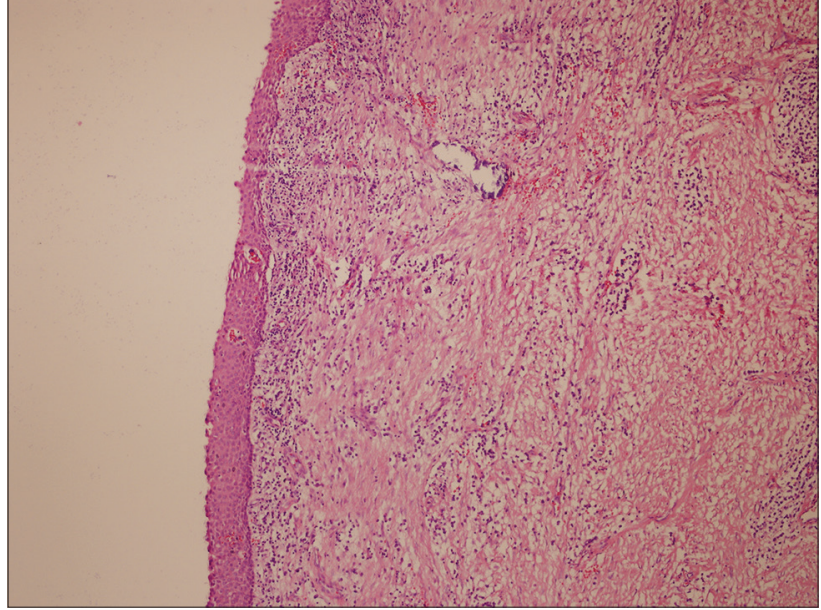

Figure 4: Photomicrograph of the lesion showing the cystic lesion lined by nonkeratinized epithelium $(\mathrm{H}$ and $\mathrm{E} \times 100)$

spread of periapical inflammation may affect the germ of the permanent tooth and may induce the formation of the cyst. Therefore, the inflammatory dentigerous cyst is usually associated with the roots of a nonvital primary tooth. ${ }^{[6,11,12]}$ According to these definitions, the presence of overlying nonvital necrotic primary mandibular first molar tooth increases the possibility of being an inflammatory type of the dentigerous cyst in the present case.

Odontogenic keratocyst, unicystic ameloblastoma, central giant cell granuloma, and a large radicular cyst must be considered in the differential diagnosis of a dentigerous cyst. Radiograph alone cannot differentiate the above-mentioned lesions, so a histopathological examination should be performed. ${ }^{[1,5]}$ Additionally, the epithelial cells lining the lumen of the dentigerous cyst possess an unusual ability to undergo metaplastic transition. Untreated dentigerous cysts rarely develop into an odontogenic tumor or a malignancy like squamous cell carcinoma. ${ }^{[1,2,5,10]}$ Therefore, the early diagnosis and treatment of a dentigerous cyst lesion creates an importance for the prevention of the occurrence of more destructive lesions.

The factors such as the size and location of the cystic lesion can change the treatment option. The available options for the treatment of these lesions in children include total enucleation of the cyst with primary closure or marsupialization. Marsupialization of the cyst is the treatment of choice which gives a chance to the unerupted tooth to erupt in large cysts; however, this technique creates notable disadvantages. To illustrate, the two-stage surgical procedure may result an intolerable procedure for a child and lifting behind a pathological tissue. ${ }^{[3,6]}$ Enucleation with primary

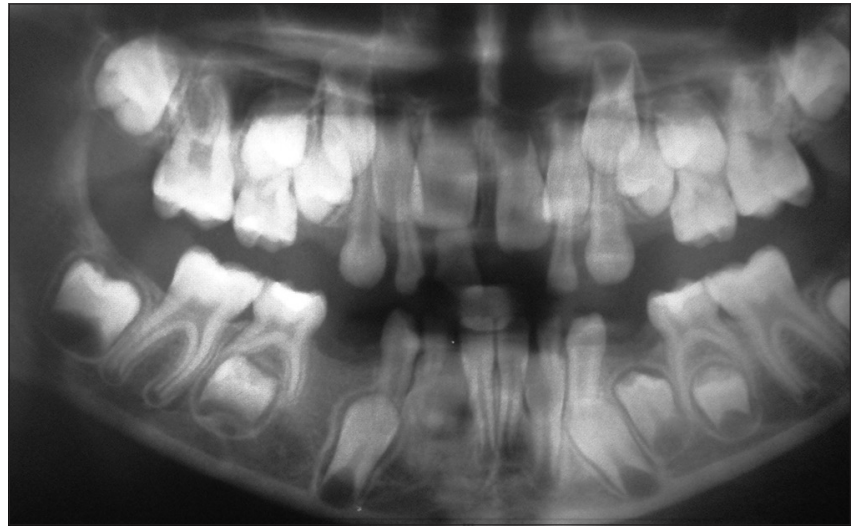

Figure 5: Postoperative panoramic radiograph (18 months later)

closure was the treatment choice in our case as the cyst was small, and the displacement of the unerupted permanent tooth was severe.

Although dentigerous cyst lesions are rare in the first decade of life, they can form in young children. For this reason, the true treatment choice with the early clinical diagnosis of these lesions may increase the rate of success. A long-term follow-up is important for the diagnosis of the recurrence as well.

\section{Financial support and sponsorship}

Nil.

\section{Conflicts of interest}

There are no conflicts of interest.

\section{REFERENCES}

1. Kirtaniya BC, Sachdev V, Singla A, Sharma AK. Marsupialization: A conservative approach for treating dentigerous cyst in children in the mixed dentition. J Indian Soc Pedod Prev Dent 2010;28:203-8.

2. Kalaskar RR, Tiku A, Damle SG. Dentigerous cysts of anterior maxilla in a young child: A case report. J Indian Soc Pedod Prev Dent 2007;25:187-90

3. Tilakraj TN, Kiran NK, Mukunda KS, Rao S. Non syndromic unilateral dentigerous cyst in a 4-year-old child: A rare case report. Contemp Clin Dent 2011;2:398-401.

4. Demirkol M, Ege B, Yanik S, Aras MH, Ay S. Clinicopathological study of jaw cysts in southeast region of Turkey. Eur J Dent 2014;8:107-11.

5. Bharath KP, Revathy V, Poornima S, Subba Reddy VV. Dentigerous cyst in an uncommon site: A rare entity. J Indian Soc Pedod Prev Dent 2011;29 6 Suppl 2:S99-103.

6. Kozelj V, Sotosek B. Inflammatory dentigerous cysts of children treated by tooth extraction and decompression - Report of four cases. Br Dent J 1999;187:587-90.

7. Passi S, Gauba K, Agnihotri A, Sharma R. Dentigerous cyst in primary dentition: A case report. J Indian Soc Pedod Prev Dent 2008;26:168-70.

8. Suresh R, Janardhanan M, Joseph AP, Vinodkumar RB, Peter S. A rare case of dentigerous cyst in a one year old child: The earliest known reported occurrence. Head Neck Pathol 2011;5:171-4.

9. Deboni MC, Brozoski MA, Traina AA, Acay RR, Naclério-Homem Mda G. Surgical management of dentigerous cyst and keratocystic odontogenic tumor in children: A conservative approach and 7-year follow-up. J Appl Oral Sci 2012;20:282-5. 
10. Desai RS, Vanaki SS, Puranik RS, Tegginamani AS. Dentigerous cyst associated with permanent central incisor: A rare entity. J Indian Soc Pedod Prev Dent 2005;23:49-50

11. Shivaprakash PK, Rizwanulla T, Baweja DK, Noorani HH. Save-a-tooth: Conservative surgical management of dentigerous cyst. J Indian Soc Pedod Prev Dent 2009;27:52-7.

12. Subramaniam P, Kumar K, Ramakrishna T, Bhadranna A. Bone regeneration with plasma-rich-protein following enucleation of traumatic bone cyst. Eur J Dent 2013;7:377-81.

\begin{tabular}{|l|l|}
\hline \multicolumn{2}{|c|}{ Access this article online } \\
\hline Quick Response Code: \\
\hline
\end{tabular}

